out injury to the surrounding healthy tissues. Another point also worthy of mention is the comparative painlessness of sarcomatous tissue. Week after week, this young man has come to my office about 4 p.m., submitted to an operation, returned home for tea, gone to his office at 6 p.m., and worked until 2 a.m. For the ensuing week I would not see him, but the daily routine of work would continue, until he would turn up smiling for the next síance. - the only home treatment being a spray at intervals of one of the hydro-carbon oils.

\title{
SUDDEN AND SIMULTANEOUS ONSET OF CEPHALIC BRUIT AND DEAFNESS.1
}

By P. McBride, M.D., F.R.C.P.E., F.R.S.E., Consulting Surgeon, Ear and Throat Department, Edinburgh Royal Infirmary.

THE case $I$ am about to relate is extremely interesting and I think in several respects stands absolutely by itself. This, of course, may be a rash statement, as it is not possible to be certain that no similar instance has been recorded; but from my researches in current literature I have been driven to the above conclusion.

The patient-a cultured clergyman, aged fifty-seven-consulted me in November, 1897. The chief complaint at the time of visit was of deafness and buzzing in the right ear. In February, on a Monday morning, he had an attack of sudden pain in the head, noises in the right ear, followed by sickness. Giddiness was not complained of, but the patient stated that he could not raise his head. There was no rise of temperature. On the following day he was much better, and able to dictate two letters. The noise and deafness in the right ear continued. Previously he heard well in both ears. On testing I found that on the right side the patient could not hear a watch tick and that in all probability there was absolute deafness for the voice, $i . e$. the patient could only hear a loud voice near the ear, and this was perceived whether the other ear was open or stopped. The tuning-fork applied to the middle line gave an uncertain result, but was better heard from the right than from the left mastoid. I may mention that all through bone-conduction seemed to be retained on the affected side.

On further examination, the right tympanic membrane was seen to be a little indrawn, while rhinoscopy revealed that both posterior and anterior nares were practically normal.

1 Communicated to the Otological Society of the United Kingdom, June 3, 1905. 
On introducing an auscultating tube into the meatus, I was somewhat astonished to hear a buzzing systolic bruit, which stopped on compression of the carotid. No pulsation was visible; the sound was heard by placing a stethoscope around the ear, being detectable above the auricle, but on this occasion most intense over the lower part of the mastoid. The intensity of the sound seemed to vary from time to time, and even from minute to minute. Rest and iodide of potassium were ordered. At an examination a few days later I have noted that the bruit was like the interrupted purring of a kitten. Heart sounds were normal, and pulses equal, while there was no detectable anomaly in the vessels around the ear. After this visit I asked the patient to see Professor Wyllie with a view to examination of his general and local state, and more particularly to ascertain the condition of the discs. Nothing abnormal was detected and Professor Wyllie was inclined to agree with my suggestion of intra-cranial aneurysm.

Nearly two years later I again saw the patient (June, 1899). He had never had a repetition of his first attack, but still heard a sound in his right ear. On auscultation now nothing could be heard and he expressed himself as feeling well. Hearing was as before, with good bone-conduction on right side. During this visit, after the patient had changed from one chair to another, the noise came back and was audible both through auscultating tube and stethoscope. In February of $1900 \mathrm{I}$ saw him again and he told me that after the least excitement he felt a fulness of the head. The bruit was audible, and I again strongly urged him to give up work. In 1901 things were as before, excepting that he occasionally felt giddy on stooping. On February 10 and 11, 1902, I again examined, and there was then no murmur to be heard either by tube or stethoscope, no matter whether the patient was sitting, stooping, or standing. In 1904 the bruit was audible only when the patient rose suddenly from a chair. My last examination was on March 6 of this year. He was feeling well-had occasionally heard booming. No bruit heard while sitting, but detectable on rising. It seemed to cease on full inspiration.

Let us now consider the signs and symptoms with a view to arriving at a diagnosis. A hale man in perfect health with no history of injury or recent disease was suddenly attacked by pain in the head and noises in the right ear, followed by sickness. Giddiness seems not to have been present in the true sense of the term and certainly did not last for any time. So far the case resembles what is known as Ménière's disease, but without 
giddiness. A peculiar feature was that hearing for the tuningfork by bone-conduction seemed to be preserved, notwithstanding the absolute deafness for external sounds. In spite of this, however, I think that no one will question that the lesion causing the deafness must have occurred in the labyrinth. Moreover, the absence of any pronounced vertigo would lead to the belief that the semicircular canals had to a great extent or completely escaped. The most probable diagnosis at first was to my mind an embolism involving that branch of the internal auditory artery which supplies the cochlea. I have only been able to find one authenticated case of embolism of the internal auditory artery on record. Gruber (Lehrbuch der Ohrenheilkunde) refers to an example of it described by Friedrich. In this instance, however, the lesion was due to endocarditis. Now, in my own case, I think that we must connect the cephalic bruit with the deafness. Moreover, from the history we must assume that this cephalic bruit began as suddenly as did the other symptoms, viz. on a Monday in February; for the murmur was so loud that the patient could not have failed to notice it had it been present before. In trying to find an explanation, we are almost driven to assume a sudden aneurysmal dilatation of one of the intra-cranial vessels. As, apart from headache and fulness, there were, after recovery from the acute attack, no symptoms, it seems useless to try to localise the affected vessel. That it belonged to the carotid system, however, seems certain, as the bruit was stopped by pressure on the common carotid in the neck. Here we are confronted by a difficulty in that the internal ear blood-supply is generally assumed to be by way of the vertebral arteries, although the internal auditory may arise from the basilar (Oppenheim, "Lehrbuch der Nervenkrankheiten," p. 679).

That the sudden deafness in this case can at first sight be hest explained by the hypothesis of an embolism seems to me clear; yet it is equally obvious that more or less grave objections exist to this assumption. An alternative explanation would be found in the suggestion that a sudden lesion resulting in dilatation of a large vessel occurred, and that the circulation was thus profoundly altered in the cochlea. Failing these two propositions, we should have to consider the cephalic bruit and the deafness as merely coincident and as not bearing to one another any causal relationa theory too improbable to be tenable.

Even if there were not the anatomical difficulty as to embolism, it would still be very remarkable that immediately on the occur- 
rence of the lesion of a large vessel the internal auditory artery should become blocked. It is, I think (as before stated), hardly conceivable that the cephalic bruit could have existed previous to the date of the acute seizure, as the patient would then have certainly noticed it. For this reason, after my careful consideration, I am rather inclined to the view that the sudden occurrence of an aneurysmal dilatation of a large vessel so modified the circulation in the right cochlea as to do irreparable injury.

\title{
LOCAL ANAESTHESIA FOR AURAL OPERATIONS, WITH SPECIAL REFERENCE TO DR. NEUMANN'S METHOD. ${ }^{1}$
}

\author{
By B. Seymour Jones, F.R.C.S.Eng.,
}

Assistant Surgeon to the Birmingham and Midland Ear and Throat Hospital.

Dr. Mnligan has kindly invited Dr. Stoddart Barr and myself to contribute a paper dealing with the several methods of procuring local anæsthesia for the performance of minor and major operations of the ear. A short survey of the methods previously known will be given, and to this will be appended a detailed description of a new process, originated and perfected by Dr. Neunamn, Assistant in Professor Politzer's Aural Clinic, Vienna.

Since the introduction of cocaine, and especially since the discovery of Schleich's infiltration method, local anasthesia has been widely and increasingly employed in the specialities and for general surgical operations. It is only in the operative treatment of ear disease that local anæsthesia has hitherto attained little success, because the great majority of anasthetic mixtures are ineffective in this region. The reason for this is to be sought in the anatomical structure of the hearing apparatus. The skin of the outer meatus and tympanic membrane are clothed with a very rexistant epithelial investment, which presents an impassable barrier to all locally applied anasthetic agents. Up to the present a mixture which has been employed for ancsthetisation of the tympanic nembrane for paracentesis corrodes the superficial epidermis before it is able to exert its anesthetic action on the part. 'This mixture consists of equal parts of cocaine hydrochloride, concentrated carbolic acid, and menthol; it is applied to the surfitce of the membrane by means of small pledgets of cottonwool at the exact site chosen for puncture. In practice this method is only relatively successful, and by ro means produces an ideal ancesthesia.

${ }^{1}$ Communicated to the Otological society of the United King dom, June 3, 1905. 